\title{
Synergetic Effect of Cationic Starch (Ether/Ester) and Pluronics for Improving Inkjet Printing Quality of Office Papers
}

\section{Mohit Sharma}

University of Coimbra

Roberto Aguado ( $\nabla$ rag@uc.pt )

University of Coimbra https://orcid.org/0000-0001-9864-1794

Dina Murtinho

University of Coimbra

Artur J. M. Valente

University of Coimbra

Paulo J. T. Ferreira

University of Coimbra

\section{Research Article}

Keywords: Cationic starch, Paper coating, Pluronics, Printing quality, Starch betainate, Whiteness

Posted Date: June 29th, 2021

DOI: https://doi.org/10.21203/rs.3.rs-647474/v1

License: (c) (1) This work is licensed under a Creative Commons Attribution 4.0 International License.

Read Full License 


\section{Synergetic effect of cationic starch (ether/ester) and}

2 Pluronics for improving inkjet printing quality of office

\section{3 papers}

5 Mohit Sharma ${ }^{\mathrm{a}}$, Roberto Aguado ${ }^{\mathrm{b}, ~}{ }^{*}$, Dina Murtinho ${ }^{\mathrm{b}}$, Artur J. M. Valente ${ }^{\mathrm{b}}$, Paulo J. T. Ferreira ${ }^{\mathrm{a}}$

7 a University of Coimbra, CIEPQPF, Department of Chemical Engineering, Rua Sílvio Lima, Pólo II

8 - Pinhal de Marrocos, 3030-790 Coimbra, Portugal

$9{ }^{b}$ University of Coimbra, CQC, Department of Chemistry, Rua Larga, PT - 3004-535 Coimbra,

10 Portugal

11

12 *rag@uc.pt (Roberto Aguado)

14 Abstract

15 Improving the printability of paper is still a relevant challenge, despite the fast development of digital communications.

16 While it is well-known that cationic starches enhance ink density, their commercial paper-grade forms are limited to

17 ethers with low degree of substitution. This work addresses the underexplored potential of highly substituted cationic

18 starch for paper coating and its combination with tri-block polymers, namely Pluronics (P123 and F127), taking

19 advantage of their supramolecular interactions with amylose chains. For that purpose, cationic starch ether and ester

20 (starch betainate), both with a degree of substitution of 0.3 , were synthesized by alkaline etherification and by

21 transesterification, respectively. Paper without any surface treatment was subjected to one-side bar coating with

22 suspensions encompassing those products and Pluronics, besides other common components. Black, cyan, yellow and

23 magenta inks were printed on all coated papers through an inkjet printer. Key properties of printing quality such as the

24 gamut area, gamut volume, optical density, print-through, inter-color bleed and circularity were measured in a controlled

25 temperature-humidity environment. For instance, a formulation with cationic starch (ether/ester) and P123 improved the

26 gamut area by 16-18\% in comparison to native starch-coated paper sheets. Interestingly, the individual assessment of

27 each component showed that cationic starch ether, starch betainate and P123 only improved the gamut area by 5.6\%,

$288.9 \%$ and $6.8 \%$, respectively. Finally, but not less importantly, starch betainate was found to quench optical brightening

29 agents to a lesser extent than cationic starch ethers.

$31 \quad$ Keywords

32 Cationic starch, Paper coating, Pluronics, Printing quality, Starch betainate, Whiteness 


\section{Introduction}

34 Paper coating formulations of printing and writing papers (P\&W) often comprise a number of different components such

35 as pigments, surfactants, binders, thickeners, dispersants, crosslinkers, optical brightening agents (OBA), and/or

36 lubricants. In each case, the composition depends on which objectives papermakers set for the end product. A careful

37 selection of coating components can therefore be used to develop a paper surface with outstanding smoothness,

38 enhanced barrier properties and, receiving less attention in the literature, improved printing properties (Sharma et al.,

39 2020). Adsorption onto cellulosic fibers occurs when the paper surface is exposed to the coating suspension, but

40 manufacturers cannot neglect the interactions between the components of such suspension, which take place beforehand,

41 from the very moment they are mixed in an aqueous media. These interactions may include competitive adsorption,

42 inclusion complex formation, and stabilization/destabilization (Sousa, De Sousa, Reis, \& Ramos, 2014).

43 The inkjet printing properties of fine papers are majorly influenced by the surface properties thereof, such as charge,

44 surface energy, roughness, permeability and surface strength (Bollström et al., 2013). A slight charge on the paper

45 surface may lead to the effective immobilization of the ink pigments onto the coated paper surface, whereas a certain

46 surface energy balance can favor a higher print density (Lundberg, Örtegren, Norberg, \& Wågberg, 2010; Stankovská,

47 Gigac, Letko, \& Opálená, 2014). Based on that, it has been shown that highly substituted cationic starch (HCS) has a

48 significant positive effect on the ink holdout (Lee et al., 2002), optical density, whiteness, water fastness and ink

49 fathering properties (Gigac, Stankovská, Opálená, \& Pažitný, 2016; Lamminmäki, Kettle, \& Gane, 2011). These

50 properties, along with the gamut area (GA), further increase in combination with amphiphilic polymers such as

51 poly(vinyl alcohol) (Baptista et al., 2016), most probably due to ease of interpolymer diffusion of ink carriers during

52 printing (Lamminmäki et al., 2011; Sousa et al., 2014).

53 While the biodegradability of native starch is obviously not under question, the biodegradability of its derivatives is too

54 often taken for granted. It has been shown that HCS ethers lose biodegradability with increasing degree of substitution

55 (DS), becoming non-biodegradable at DS $\geq 0.54$ (Bendoraitiene, Lekniute-Kyzike, \& Rutkaite, 2018). In this context,

56 starch betainate (SB) rises as a convincing alternative, not only because betaine is naturally found, unlike conventional

57 cationizing reagents, but also because the ester bonds of SB are clearly more labile than ether bonds (Auzély-Velty \&

58 Rinaudo, 2003). Likewise, starch betainate (SB), a cationic starch ester, was suggested for the improvement of paper

59 strength since the first work reporting its synthesis (Granö, Yli-Kauhaluoma, Suortti, Käki, \& Nurmi, 2000). However,

60 as far as we know, no study has addressed the influence of SB on the printing properties of fine papers. This issue is

61 addressed in the present work, evaluating coating formulations comprising SB and other interesting amphiphilic

62 polymers, namely Pluronics.

63 Pluronics ${ }^{\circledR}$ is BASF's trade name for the less commonly called poloxamers. This trade name comprises non-ionic,

64 water-soluble, triblock copolymers of polyethylene oxide (PEO) and polypropylene oxide (PPO) units. Interestingly enough, they generally form inclusion complexes with starch in aqueous solution. This kind of binding has a significant effect on the dispersion performance and can be explained by hydrophobic interactions between hydrophobic parts of Pluronics ${ }^{\circledR}$ macromolecules and the cavities of the amylose helix (Petkova-Olsson, Altun, Ullsten, \& Järnström, 2017). Additionally, the micellar structure of these non-ionic surfactants also influences the adsorption onto the surface of 
cellulosic materials, which is enhanced in the presence of cationic polymers (Liu, Vesterinen, Genzer, Seppälä, \& Rojas, 2011; Liu et al., 2010).

In light of the aforementioned hypotheses and previous findings, Pluronics was combined with cationic starches in order to observe their effect on the inkjet printing quality parameters. Paper sheets were coated using different concentrations of SB, HCS, Pluronics (P127 and F127), precipitated calcium carbonate (PCC), alkyl ketene dimer (AKD) and optical brightening agent (OBA). This study also illustrates the use of a statistical tool to design the coating experiments and to identify the most important factors to be considered for improving the paper printability. A comparison of HCS and SB coatings was also explored, discussing their influence on the whiteness of paper, given that the interaction between cationic polymers and OBAs, generally anionic, has been pointed out as a major cause of fluorescence quenching (Shi et al., 2012).

\section{Materials and Methods}

\section{$81 \quad$ Materials}

82 Native corn starch (NS), $\alpha$-amylase (in standard buffer solution, pH 5.8), PCC, OBA and AKD were of industrial origin.

83 3-Chloro-2-hydroxypropyltrimethyl ammonium chloride (CHPTAC), Pluronics ${ }^{\circledR}$ P123 (MW 5750 g mol ${ }^{-1}$, PEO 30

$84 \%$ wt. and CMC of $0.313 \mathrm{mM}$ at $20^{\circ} \mathrm{C}$ ) (Alexandridis, Holzwarthf, \& Hatton, 1994) and Pluronics ${ }^{\circledR}$ F127 (MW $\sim 12600 \mathrm{~g} \mathrm{~mol}^{-1}$, PEO-70 \%wt. and CMC of $0.56 \mathrm{mM}$ at $25^{\circ} \mathrm{C}$ ) (Thapa, Cazzador, Grønlien, \& Tønnesen, 2020) were purchased from Sigma-Aldrich. Betaine hydrochloride (99\%) was purchased from Alfa Aesar and used as-is for transesterification. All solvents were purified or dried prior to use the standard procedures. Other commercially available compounds were used without further purification.

\section{Synthesis of HCS and SB}

91 Native starch was mildly hydrolyzed with $\alpha$-amylase $\left(0.45 \mu \mathrm{L} \mathrm{g}^{-1}\right.$ of starch), under continuous stirring, at $80{ }^{\circ} \mathrm{C}$ for 5 $92 \mathrm{~min}$. The temperature was raised up to $90-95^{\circ} \mathrm{C}$ for $15 \mathrm{~min}$. Then, the starch solution was cooled down and absolute ethanol was added to precipitate the polysaccharide, hereinafter referred to as "cooked starch". Cooked starch was then vacuum filtered, dried and stored in an oven at $50{ }^{\circ} \mathrm{C}$. This pretreatment is common to the synthesis of both $\mathrm{HCS}$ and SB.

HCS was synthesized as described elsewhere (Haack, Heinze, Oelmeyer, \& Kulicke, 2002). Briefly, $10 \mathrm{~g}$ of cooked or native starch was converted into HCS using $33.5 \mathrm{~mL}$ of CHPTAC (60\% wt.) and $5.9 \mathrm{~g}$ of NaOH. The reaction was carried out for $24 \mathrm{~h}$ at $70{ }^{\circ} \mathrm{C}$ in $100 \mathrm{ml}$ of distilled water. The reaction mixture was then neutralized with a $0.1 \% \mathrm{HCl}$ 99 solution.

100 Starch betainate (SB) was synthesized, as described in a previous paper (Sharma, Aguado, Murtinho, Valente, \&

101 Ferreira, 2021), through the transesterification of starch with methyl betainate (MeBetCl) in polar aprotic solvents. $24 \mathrm{~g}$

102 of betaine hydrochloride was first esterified to synthesize $\mathrm{MeBetCl}$ using $11.3 \mathrm{~mL}$ of thionyl chloride and $75 \mathrm{~mL}$ of 
methanol, under reflux, for $4 \mathrm{~h}$ at $70^{\circ} \mathrm{C}$. MeBetCl was recovered through evaporation of methanol followed by trituration in diethyl ether and, finally, the crude product was dried under high vacuum. Then, $10 \mathrm{~g}$ of starch were converted into SB using $20.8 \mathrm{~g}$ of MeBetCl in $N, N$-dimethylformamide (DMF), $100 \mathrm{~mL}$. Prior to transesterification, cooked starch was pre-activated in $\mathrm{NaOH} /$ ethanol. The reaction was carried out for $24 \mathrm{~h}$ at $70{ }^{\circ} \mathrm{C}$. HCS and SB were precipitated by adding ethanol (alcohol/water $>10, \mathrm{v} / \mathrm{v}$ ), vacuum filtered and washed with absolute ethanol, followed by drying at $50{ }^{\circ} \mathrm{C}$.

\section{Characterization of synthesized cationic starches}

111 Attenuated Total Reflectance-Fourier Transform Infrared (ATR-FTIR) spectroscopy, ${ }^{1} \mathrm{H}$-nuclear magnetic resonance 112 ('H-NMR) spectroscopy and viscometry analysis were performed to characterize the synthesized cationic starches.

113 ATR-FTIR spectra were recorded by using an Agilent Cary 630 spectrometer, from 750 to $3000 \mathrm{~cm}^{-1}$, at a resolution of $1144 \mathrm{~cm}^{-1}$ and 64 scans per sample. NMR spectra were obtained from a Bruker Biospin $\mathrm{GmbH}$ spectrometer, at $400 \mathrm{MHz}$, 115 using $\mathrm{D}_{2} \mathrm{O}$ as solvent. The degree of substitution was calculated from the area of the singlet assigned to the methyl 116 protons of the quaternary ammonium group. The reliability of this result was confirmed by measuring the nitrogen 117 percentage of samples on a Fisons Instruments EA 1108 CHNS-O elemental analyzer.

\section{Paper coating}

120 NS was used as a common component for preparing all formulations in this work. For that, NS was cooked as described earlier, and then cooled down to $50^{\circ} \mathrm{C}$ instead of precipitated. An industrial calendered uncoated paper (base paper, BP), produced from bleached eucalyptus kraft pulp with a basis weight of $\sim 78 \mathrm{gm}^{-2}$, was used as substrate for performing surface coating.

124 Coating of BP was performed using a Mathis laboratory coater, with a pre-drying infrared system coupled to the 125 applicator bar (SVA-IR-B). An applicator roll with the diameter of $0.13 \mathrm{~mm}$, in conjunction with a velocity of $6 \mathrm{~m} \mathrm{~min}^{-1}$ 126 and intermediate load at both sides, was used to achieve 1.5 to $3 \mathrm{~g} \mathrm{~m}^{-2}$ per side, on the basis of dry coating weight. 127 Coated paper sheets were air dried at room temperature.

128 Besides NS, BP sheets were coated with SB, HCS, P123, F127, PCC, and combinations thereof. Coatings were performed using $8 \%, 16 \%$ and $24 \%$ of total solids coating weight of each of these components, and several combinations of them were tested at said concentrations. The coating compositions resulting from individual components (with NS) and combinations thereof are shown in Table 1 and 2 , respectively.

132 The surface weight gain was calculated by the difference between basis weights (ISO standard 536:1995) of the air-dried 133 coated paper sheet and the respective BP sheet. Before characterization, all coated papers were kept at controlled 134 temperature $\left(23^{\circ} \mathrm{C} \pm 1\right)$ and humidity (RH $\left.50 \% \pm 2\right)$. For each run, three numbers for paper sheets were coated and characterized for evaluating the printing quality. 
138 Table 1. Composition of coating components expressed as \%w/w, on the basis of dry coating weight.

\begin{tabular}{|c|c|c|c|c|c|c|c|c|c|c|c|c|c|c|}
\hline \multirow{2}{*}{ Ingredients } & \multicolumn{14}{|c|}{ Coating formulations } \\
\hline & \multicolumn{4}{|c|}{$\mathrm{HCS} / \mathrm{SB}$} & \multicolumn{3}{|l|}{ P123 } & \multicolumn{3}{|c|}{ F127 } & \multicolumn{3}{|l|}{ PCC } & \multirow[t]{2}{*}{ Reference } \\
\hline$\overline{\mathrm{HCS} / \mathrm{SB}}$ & 8 & 16 & 24 & 16 & & & & & & & & & & \\
\hline P123 & & & & & 8 & 16 & 24 & & & & & & & \\
\hline F127 & & & & & & & & 8 & 16 & 24 & & & & \\
\hline PCC & & & & & & & & & & & 8 & 16 & 24 & \\
\hline OBA & 6 & 6 & 6 & & 6 & 6 & 6 & 6 & 6 & 6 & 6 & 6 & 6 & 6 \\
\hline AKD & 0.4 & 0.4 & 0.4 & 0.4 & 0.4 & 0.4 & 0.4 & 0.4 & 0.4 & 0.4 & 0.4 & 0.4 & 0.4 & 0.4 \\
\hline NS & 85.6 & 77.6 & 69.6 & 83.6 & 85.6 & 77.6 & 69.6 & 85.6 & 77.6 & 69.6 & 85.6 & 77.6 & 69.6 & 93.6 \\
\hline
\end{tabular}

139

140 Table 2. Composition of coating components for the interaction study, expressed as \%w/w, on the basis of dry coating 141 weight.

\begin{tabular}{|c|c|c|c|c|c|c|c|c|c|c|}
\hline \multirow{3}{*}{$\begin{array}{l}\text { Ingredients } \\
\mathrm{HCS} / \mathrm{SB}\end{array}$} & \multicolumn{10}{|c|}{ Coating formulations } \\
\hline & \multicolumn{4}{|c|}{$\mathrm{HCS} / \mathrm{SB}+\mathrm{P} 123$} & \multicolumn{4}{|c|}{$\mathrm{HCS} / \mathrm{SB}+\mathrm{P} 123+\mathrm{PCC}$} & \multicolumn{2}{|c|}{ Reference } \\
\hline & 16 & 16 & 16 & 16 & 16 & 16 & 16 & 16 & & \\
\hline $\mathrm{P} 123$ & 8 & 16 & 24 & 16 & 8 & 16 & 24 & 16 & & \\
\hline PCC & & & & & 16 & 16 & 16 & 16 & & \\
\hline OBA & 6 & 6 & 6 & & 6 & 6 & 6 & & 6 & \\
\hline AKD & 0.4 & 0.4 & 0.4 & 0.4 & 0.4 & 0.4 & 0.4 & 0.4 & 0.4 & 0.4 \\
\hline NS & 69.6 & 61.5 & 53.6 & 67.6 & 53.6 & 43.6 & 37.6 & 51.6 & 93.6 & 99.6 \\
\hline
\end{tabular}

\section{Statistical analysis}

144 In order to observe the interactions between coating components and their impact on the printing quality of coated 145 papers, JMP software was used as a statistical tool for the design of experiments and data analysis. In this study, four 146 continuous factors, namely HCS, P123, PCC and OBA, were selected, each at two levels (0 and 16\%), and a full 147 factorial design with two center points was chosen to design the coating experiments. A total number of 18 runs were 148 performed to evaluate the effect of these factors and their ternary interactions on the printing quality, namely: GA; OD 149 for cyan, magenta, yellow, and black; PT; inter-color bleed (ITCB), and circularity for black color in the responses.

\section{$151 \quad$ Printing quality}

152 The printing quality was evaluated as reported elsewhere (Lourenço, Gamelas, Sarmento, \& Ferreira, 2020). Briefly, the 153 coated papers were printed using HP Officejet Pro 6230 inkjet printer, having cyan, magenta, yellow, and black color 154 ink cartridges. The printed sheets were air dried for $4 \mathrm{~h}$ under controlled conditions of temperature and humidity.

155 The GA is the area of the hexagon resulting from the $\mathrm{a}^{*}$ and $\mathrm{b}^{*}$ coordinates of six printed colors (red, green, blue, cyan, 156 magenta, and yellow), where $\mathrm{a}^{*}$ axis represents the color from green to red and axis $\mathrm{b}^{*}$ represents the color from blue to 157 yellow. It was determined by measuring the values of CIE L*a*b* coordinates for six color spots, including three base 158 colors (cyan, magenta and yellow) and other three complimentary colors (red, green and blue). For that, the "X-Rite Eye 159 One XTreme UV Cut" spectrophotometer was placed on each printed color spot, activating the UV light (D50, $2^{\circ}$ ). The 
160 readings were taken in the sequence of red, green, blue, cyan, magenta, and yellow color spots. Additionally, CIE

$161 \mathrm{~L} * \mathrm{a} * \mathrm{~b} *$ values for black and white colors were measured to estimate the gamut volume (GV) of printed paper sheets.

162 In order to evaluate the other printing properties, such as OD and PT, the QEA PIAS-II spectrophotometer was used 163 with a low resolution optical module $(33 \mu \mathrm{m} / \mathrm{pixel}$ with visual area of $21.3 \mathrm{~mm} \times 16 \mathrm{~mm})$, along with the software PIAS

164 II, based on ISO 13660 quality standards, for processing the images. The PT of a printed paper requires the measurement 165 of $\mathrm{L}^{*} \mathrm{a} \mathrm{b}^{*}$ values on the opposite side, in contrast with the non-printed area of the same paper sheet. The transmitted 166 light intensity from a specific area of each color (black, white, cyan, magenta, and yellow) was measured using QEA 167 PIAS-II, and thus PT and OD were calculated from the following equations:

where $L^{*}, a^{*}, b^{*}$ are the CIE chromatic coordinates, and the subscripts $u$ and $p$ refer to areas of unprinted and back of the printed black spot, respectively.

173 The other printing properties, namely ITCB and circularity (black), were also evaluated by means of QEA PIAS-II with 174 high resolution module $(5 \mu \mathrm{m} /$ pixel with $3.2 \mathrm{~mm} \times 2.4 \mathrm{~mm})$. This was used to measure the raggedness, which can be defined as the geometric distortion of the line and dots, given by the standard deviation of the residue from the lines and dots adjusted to their ideal limit. The higher the raggedness, the worse the ITCB and circularity.

\section{Paper properties}

179 The surface hydrophilicity for SB-coated papers was evaluated by contact angle goniometry. The static water contact

180 angle (WCA) was measured in an OCA 20 goniometer (Dataphysics, Germany) using the sessile drop method. A droplet 181 of deionized water $(10 \mu \mathrm{L})$ was automatically poured onto the coated paper surface. After settling, the formed angle was 182 measured by fitting the Young-Laplace equation to the drop profile. Bendtsen roughness (ISO 5636-3, 8791-2) and 183 Gurley air permeability (ISO 5636/5) were also measured for coated papers using appropriate testers from Flank. 184 Whiteness (CIE W D65/10) of coated papers was measured using D65 illumination in the Elrepho spectrophotometer. 185 The average value and the standard deviation of four independent measures are reported for CA, Bendtsen roughness, 186 Gurley air permeability and whiteness. This last property was related to the performance of OBA, as fluorescence 187 emission spectra of solutions containing OBA were recorded by means of a FluoroMax 4 spectrofluorometer from 188 Horiba.

189 The kinematic viscosity was determined using a size 100 Cannon-Fenske viscometer in a thermostatic bath (TAMSON TV 2000) set at $40{ }^{\circ} \mathrm{C}$. Measurements followed the ISO 3105 standard. Polymer solutions were prepared with a concentration of $5 \mathrm{mg} \mathrm{cm}^{-3}$ in $1 \mathrm{M} \mathrm{NaOH} / \mathrm{H}_{2} \mathrm{O}$ (for $\mathrm{HCS}$ ) and DMSO (for $\mathrm{SB}$ ). The thermogravimetric analysis (TGA) was carried out on a thermo-microbalance TG 209 F3 Tarsus, from Netzsch Instruments. Samples were heated from 40 ${ }^{\circ} \mathrm{C}$ to $600{ }^{\circ} \mathrm{C}$, under a flow of nitrogen $\left(20 \mathrm{~mL} \mathrm{~min}^{-1}\right)$, with a heating rate of $10{ }^{\circ} \mathrm{C} \mathrm{min}{ }^{-1}$. TGA was performed for filter 
194 paper coated with P123, F127 and SB. A filter paper was cut into pieces $(5 \mathrm{~cm} \times 2 \mathrm{~cm})$ and Pluronics P123/F127 were 195 absorbed in this cellulosic substrate. This was carried out with a 10\% Pluronic aqueous solution and a LayerBuilder dip 196 coater from KSV. Cellulose substrates were dipped into the solution for $3 \mathrm{~min}$, pulled out and air-dried. The same 197 procedure was followed for 10\% SB and 10\% P123/F127 + 10\% SB aqueous solutions.

198

\section{Results and discussion}

\section{Synthesis of SB and HCS}

201 Figure 1a presents the ATR-FTIR spectra for synthesized cationic starches from etherification and transesterification,

202 using respectively CHPTAC and betaine hydrochloride, in comparison to the NS spectrum. The absorption peaks at $2033300 \mathrm{~cm}^{-1}, 2912 \mathrm{~cm}^{-1}, 1648 \mathrm{~cm}^{-1}$ can be assigned to the $-\mathrm{OH},-\mathrm{CH}_{2}$ stretching vibrations, and $\mathrm{H}_{2} \mathrm{O}$ bending vibration 204 due to water sorption, respectively. Additionally, peaks at $994 \mathrm{~cm}^{-1}$ can be attributed to the ether bonds and the 205 absorption band at $897 \mathrm{~cm}^{-1}$ can be assigned to $\mathrm{C} 1-\mathrm{H}$ bending in starch. Compared to cooked starch, a new prominent 206 peak at $1473 \mathrm{~cm}^{-1}$ can be observed due to the quaternary ammonium group attached to the anhydroglucose unit (AGU) 207 (Hebeish, Higazy, El-Shafei, \& Sharaf, 2010; Wang \& Cheng, 2009). Furthermore, the absorption band at $1750 \mathrm{~cm}^{-1}$ is 208 assigned to the ester bond in SB.

209 Figure $1 \mathrm{~b}$ shows the ${ }^{1} \mathrm{H}-\mathrm{NMR}$ spectra for HCS and SB, compared to the spectrum of cooked starch. The singlet at 3.28 $210 \mathrm{ppm}$ is assigned to the nine hydrogens of methyl groups of the quaternary ammonium. The resonances from 3.5 to $4 \mathrm{ppm}$ 211 represent the hydrogens attached to carbons 2, 4, 5, 6 (H-6 and H-6'), and 3 of AGU, typically in that order. The doublet 212 for the $\mathrm{H}-1(\alpha)$ anomeric proton lies downfield (5.35 ppm). There was a certain shift upfield and broadening of all signals 213 upon cationization. No impurities were detected in SB, but the HCS spectrum displayed a singlet at $3.33 \mathrm{ppm}$ and a 214 quadruplet at $3.65 \mathrm{ppm}$, none of which belong to the canonical structure of cationic starches. The former could be due to 215 quaternary ammonium groups arising from substitution on hydroxypropyl chains, instead of the hydroxyl groups of 216 AGU. 
a

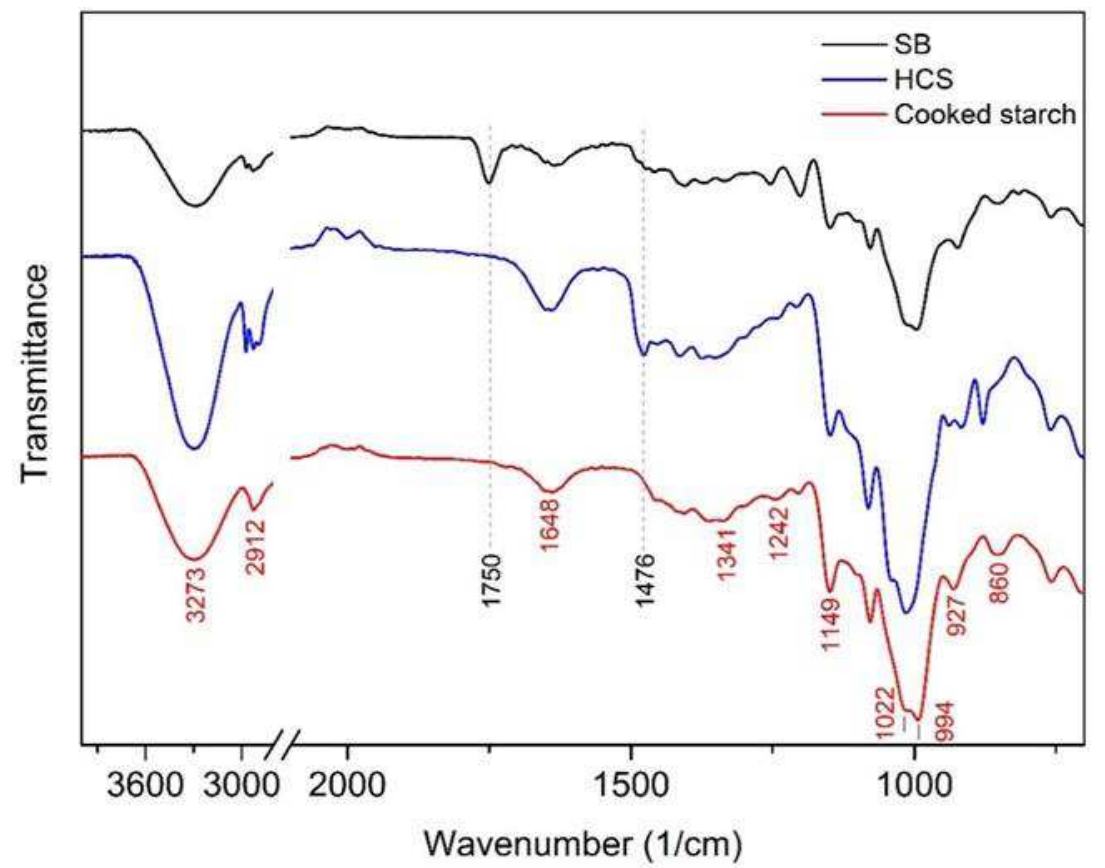

b
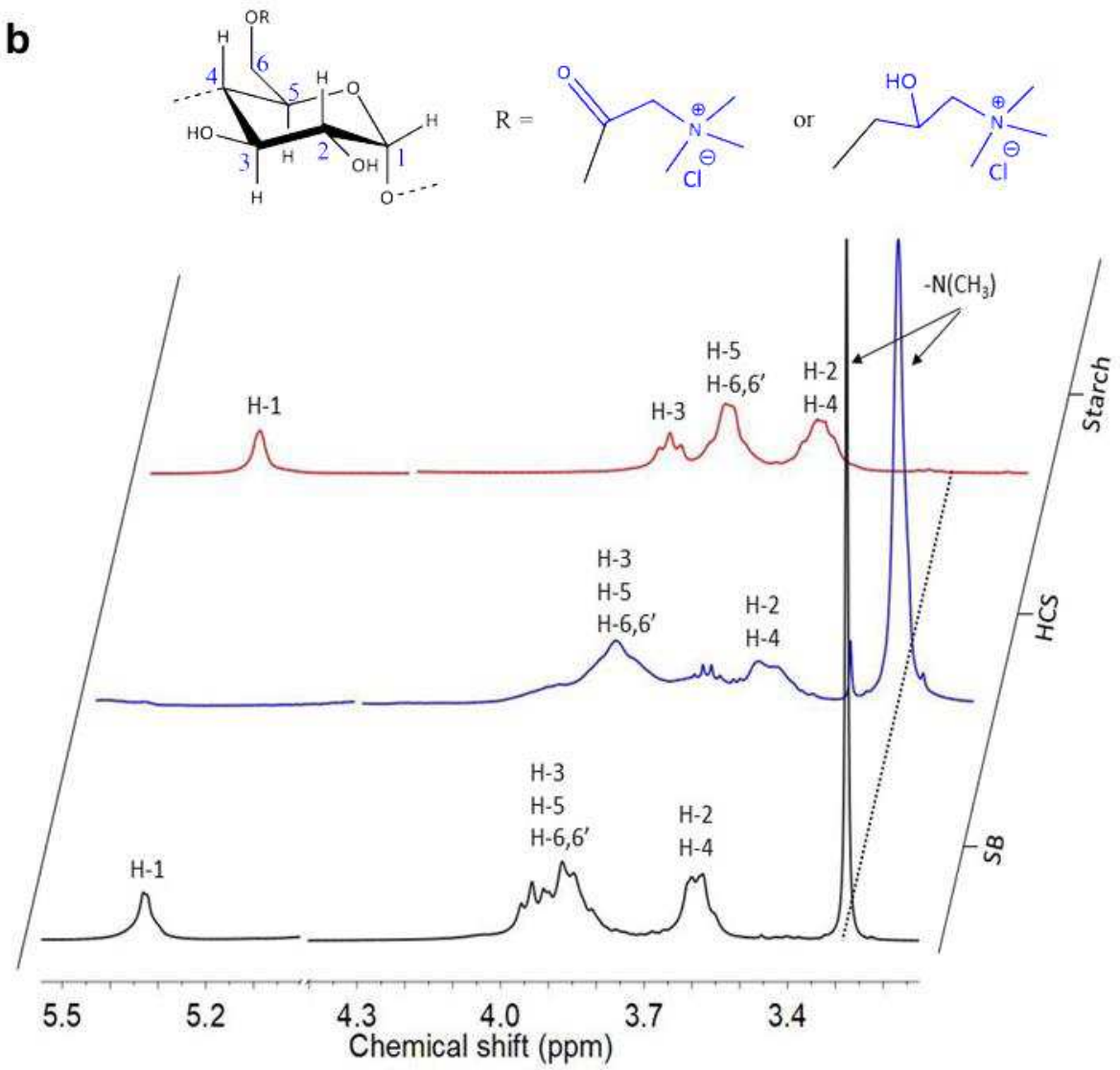

$/ \mathrm{Cl}^{\circ}$ 
An important hypothesis regarding the reaction is that enzymatic cooking improves its efficiency. Figure 2a shows the effect of cooking and reaction time on the DS of the synthesized HCS. It can be observed that the DS increases from 0.20 to 0.33 and from 0.34 to 0.43 with the increase in the reaction time from 3 to $24 \mathrm{~h}$, when native and cooked starches were used as raw materials for the etherification reactions, respectively. This is likely due to the formation of more porous starch granules, which facilitates the access of the reagent to hydroxyl groups (Huber \& BeMiller, 2001). It was also observed that the cooking of starch enables the homogeneous dispersion of starch granules in the solvent by increasing the solubility and decreasing its viscosity, as seen in Figure 2b (Gao, Luo, Fu, Luo, \& Peng, 2012). Undoubtedly, due to the cleavage of 1-4 $\alpha$-D-glucopyranosyl linkages of amylose and amylopectin, the inherent viscosity decreases with the enzymatic pre-treatment, from $199.4 \mathrm{~cm}^{3} \mathrm{~g}-1$ (NS) to $151.8 \mathrm{~cm}^{3} \mathrm{~g}^{-1}$ (cooked starch). The viscosity was further reduced by $43-45 \%$ when using them in etherification. Likewise, the hydrolysis of starch molecules in highly alkaline media and at high temperature is evidenced by a loss of viscosity after functionalization. Nonetheless, after reaction times beyond $3 \mathrm{~h}$, further hydrolysis is either negligible or compensated by the effects of cationization on polymer-solvent interactions.

a

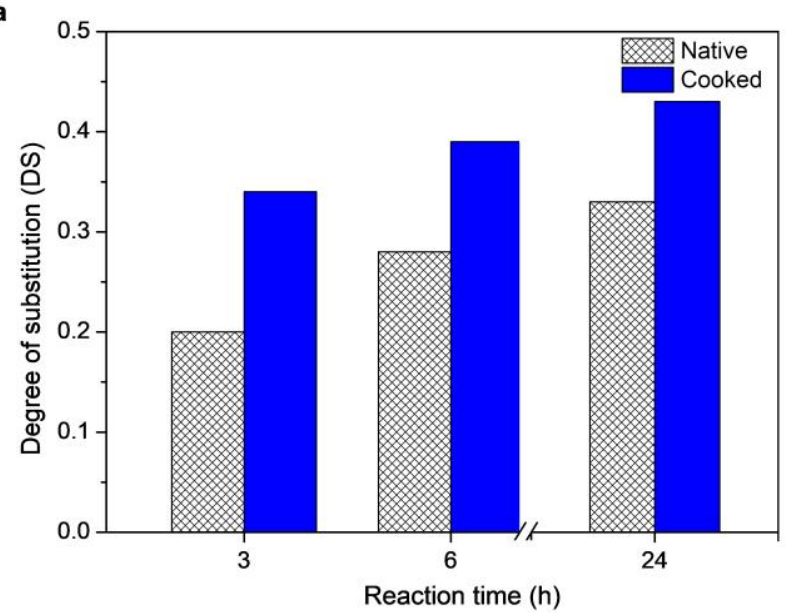

b

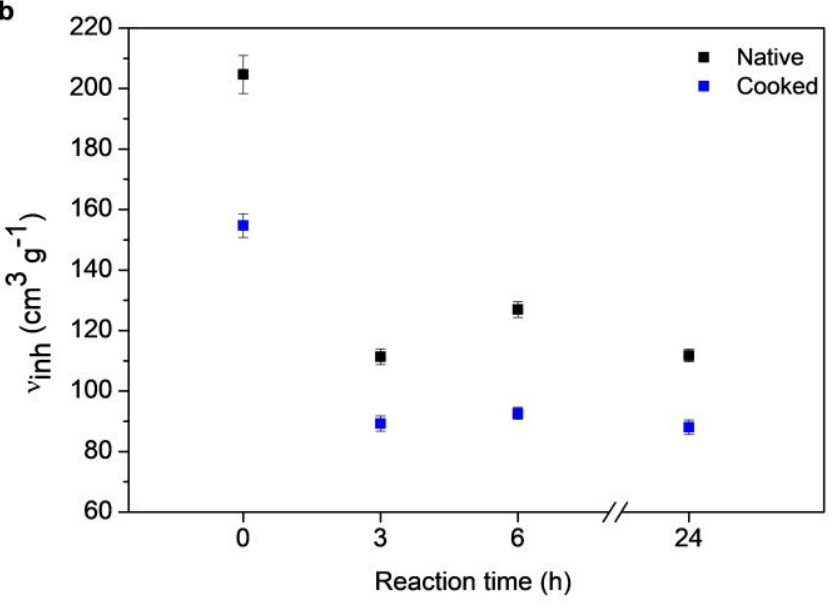

Figure 2 Effect of reaction time and enzymatic cooking on degree of substitution (A) and inherent viscosity (B) of HCS.

Like etherification, the increase in DS and decreasing in viscosity were also observed in the synthesis of SB. However, DS increased much more abruptly, from 0.01 to 0.33 , when using NS and cooked starch in the transesterification reaction, respectively, proving the poor reaction efficiency with NS. Given that the inherent viscosity decreased by $\sim 73 \%$, starch faced higher depolymerization during functionalization, mostly due to the previous alkalization of starch at high temperature.

\section{Paper printing properties}

Both native starch and CS require cooking before adding other coating components to prepare a uniform coating solution. It should be noted that the other coating components (PCC, Pluronics, OBA and AKD) were always added after cooling down the starch solution to $50^{\circ} \mathrm{C}$. It should be stressed that the P123 and F127 have critical micelle concentrations of $0.313 \mathrm{mM}\left(20^{\circ} \mathrm{C}\right)$ and $0.56 \mathrm{mM}\left(25^{\circ} \mathrm{C}\right)$, respectively. These values are lower than the amount of 
248 Pluronics used in the experiments reported here; additionally, the critical micelle temperatures of these surfactants are

249 well below $50^{\circ} \mathrm{C}$ which also support that Pluronics are in the micelle form (He \& Alexandridis, 2018).

250 In order to prepare the coating formulations, corn native starch was used as host component and cooked using $\alpha$ -

251 amylase enzyme in aqueous medium at $80^{\circ} \mathrm{C}$, for $5 \mathrm{~min}$. CS was then added and cooked together with native starch at $25290-95^{\circ} \mathrm{C}$ for $15 \mathrm{~min}$. The starch solution was cooled down for $15 \mathrm{~min}$.

\section{Gamut area}

255 It was observed that the GA, presented in Figure 3a, increased by $8.6 \%, 9 \%$, and $12.5 \%$ using $8 \%, 16 \%$ and $24 \%$ dry 256 solids content of SB, respectively, compared to NS coating. Plausibly, the high DS led to higher deposition of SB on the 257 paper surface, resulting into improved GA (Niegelhell et al., 2018).

258 Besides charge density, addition of SB slightly increased the hydrophobicity of the paper surface and smoothness;both 259 also contributed to improve GA (Gigac, Stankovska, \& Pazitny, 2016) (Gigac, Stankovska, et al., 2016). Table 4 can be 260 referred to for the Bendtsen roughness, and contact angle values for SB coated papers.

261 Similarly to GA, GV, which considers the color luminance L, besides a and b, also increased with increasing SB 262 concentration. The maximum increase was observed as $16.4 \%$ using $24 \%$ of SB, compared to NS coating (refer Table 263 4).
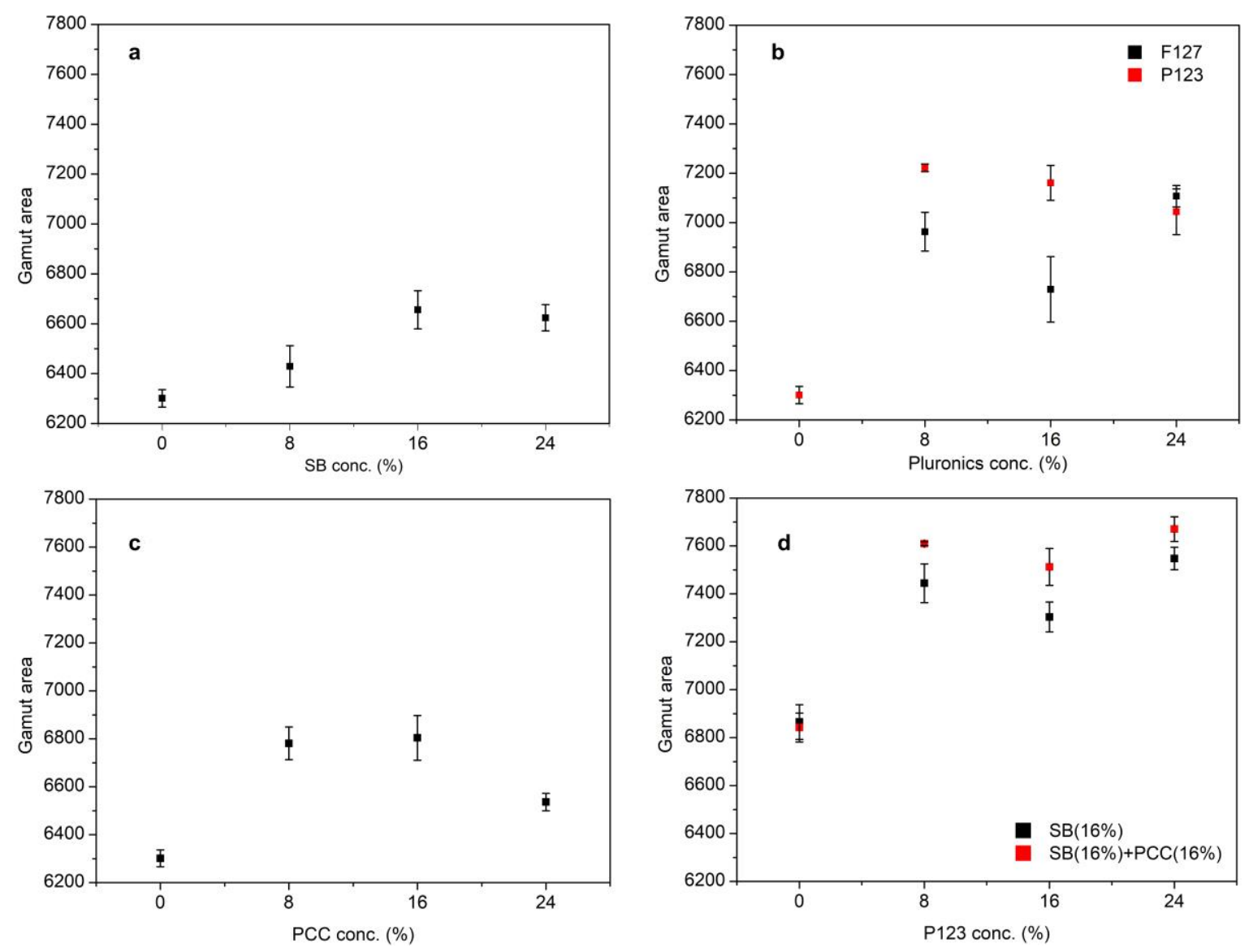

Figure 3 Effect of different concentrations of SB (a), Pluronics (b), PCC (c), and their combinations (d) on GA. 
267 Table 3 Properties of coated papers using different concentrations of SB, Pluronics (P123 and F127), and their 268 combination in coating formulations.

\begin{tabular}{llllllll}
\hline & $\begin{array}{l}\text { Conc. } \\
(\%)\end{array}$ & $\begin{array}{l}\text { Roughness } \\
(\mathrm{mL} / \mathrm{min})\end{array}$ & $\begin{array}{l}\text { Gurley } \\
(\mathrm{mL} / \mathrm{min})\end{array}$ & $\begin{array}{l}\text { Contact angle } \\
\left(^{\circ}\right)\end{array}$ & Whiteness & $\begin{array}{l}\text { Gamut volume Weight gain } \\
/ 10^{3}\end{array}$ & $\begin{array}{l}\text { W/m } \\
(\mathrm{g})\end{array}$ \\
\hline Reference $(\mathrm{NS})$ & $329 \pm 13$ & $318 \pm 7$ & $72 \pm 1$ & $162.8 \pm 1.3$ & $132 \pm 1$ & $1.8 \pm 0.3$ \\
\hline \multirow{3}{*}{ SB } & 8 & $324 \pm 14$ & $379 \pm 14$ & $75 \pm 2$ & $162.3 \pm 0.5$ & $146 \pm 1$ & $2.5 \pm 0.2$ \\
& 16 & $311 \pm 7$ & $397 \pm 4$ & $77 \pm 2$ & $164.5 \pm 0.3$ & $151 \pm 1$ & $1.9 \pm 0.2$ \\
& 24 & $376 \pm 9$ & $420 \pm 16$ & $79 \pm 1$ & $164.1 \pm 0.7$ & $153 \pm 1$ & $2.3 \pm 0.3$ \\
\hline & 8 & $368 \pm 9$ & $407 \pm 6$ & $50 \pm 3$ & $165.1 \pm 0.2$ & $153.3 \pm 0.4$ & $2.9 \pm 0.2$ \\
P123 & 16 & $379 \pm 30$ & $381 \pm 5$ & $43 \pm 2$ & $165.6 \pm 0.2$ & $152 \pm 2$ & $2.9 \pm 0.1$ \\
& 24 & $357 \pm 9$ & $354 \pm 9$ & $47 \pm 1$ & $165.8 \pm 0.4$ & $150 \pm 2$ & $3.0 \pm 0.2$ \\
\hline & 8 & $378 \pm 38$ & $356 \pm 5$ & $63 \pm 3$ & $163.6 \pm 0.6$ & $145 \pm 2$ & $2.4 \pm 0.2$ \\
F127 & 16 & $363 \pm 28$ & $325 \pm 50$ & $57 \pm 1$ & $163.4 \pm 0.4$ & $141 \pm 3$ & $2.7 \pm 0.1$ \\
& 24 & $329 \pm 18$ & $444 \pm 13$ & $53 \pm 2$ & $162.2 \pm 0.7$ & $150 \pm 1$ & $2.7 \pm 0.2$ \\
\hline & 8 & $414 \pm 37$ & $347 \pm 5$ & $75 \pm 2$ & $160.9 \pm 0.3$ & $149 \pm 1$ & $2.5 \pm 0.3$ \\
PCC & 16 & $370 \pm 15$ & $381 \pm 11$ & $83 \pm 2$ & $161.3 \pm 0.1$ & $146 \pm 1$ & $2.5 \pm 0.2$ \\
& 24 & $365 \pm 5$ & $367 \pm 2$ & $80 \pm 2$ & $162.5 \pm 1.1$ & $143 \pm 1$ & $2.7 \pm 0.1$ \\
\hline \multirow{2}{*}{ P123 } & 8 & $375 \pm 22$ & $376 \pm 21$ & $51 \pm 3$ & $164.9 \pm 1.7$ & $162 \pm 3$ & $2.4 \pm 0.1$ \\
(with SB) & 16 & $383 \pm 36$ & $321 \pm 9$ & $48 \pm 2$ & $165.4 \pm 0.8$ & $161 \pm 2$ & 2.8 \\
& 24 & $368 \pm 13$ & $374 \pm 13$ & $40 \pm 3$ & $163.6 \pm 0.5$ & $164 \pm 2$ & $2.7 \pm 0.1$ \\
\hline
\end{tabular}

270 In Figure 3b, the GA for different concentrations of Pluronics P123 and F127 is presented. GA is improved by $14.6 \%$ using $8 \%$ of P123 in the coating solution; however, the GA is further reduced by increasing the P123 concentration from $8 \%$ up to $24 \%$. For F127, the $8 \%$ addition improves the GA by $10.5 \%$, but further increase in the concentration of F127, from 8 up to $16 \%$, reduces the GA as well. However, the use of $24 \%$ of F127 showed almost equal GA increase as $24 \%$ of P123, 11.8\% and 12.8\%, respectively. The increase of GA can be explained by the amphiphilic nature of Pluronics, which facilitates the strong adsorption of these components on cellulosic surfaces (Liu et al., 2010). Additionally, Pluronics form inclusive complexes with starches, leading to the formation of self-supporting flocs in the coating formulation, and enhancing the dispersion of other coating components (Petkova-Olsson et al., 2017; Petkova-Olsson, Ullsten, \& Järnström, 2016). Interestingly enough, the lowest amount of P123 and F127 (8\%) was found to be more favorable to improve GA. This area was also improved by $\sim 7.9 \%$ in the presence of PCC at a concentration of $8 \%$ or

$28016 \%$ (Figure 3c), which is related to the gain in hydrophobicity of the paper surface. However, roughness increased with 281 the presence of PCC and GA was further decreased by $3.7 \%$ with a large content of PCC (24\%) in the coating 282 formulation.

283 The effect of P123 coatings in combination with SB (16\%) and SB (16\%)/PCC (16\%) is displayed in Figure 3d. It is 284 observed that GA increases by $8.5-9 \%$ using P123 or a mixture of P123 and PCC. It was further improved significantly 285 by $16-20 \%$ and $19-22 \%$ with the presence of SB/P123 and SB/P123/PCC, respectively. This increase in GA can be 286 explained by the sorption of Pluronics on the cellulosic surface, which increases in combination with a highly cationic 287 polymer (Liu et al., 2011, 2010). Moreover, formation of amylose-Pluronics inclusion complexes may also facilitates the 288 immobilization of the ink pigments on the coated paper surface, improving GA.

289 TGA contributes to understand the adsorption of Pluronics in the presence of a cationic polymer. Figure 4 (a) and 4 (b) 290 represent the TGA and DTG curves of dip-coated paper samples, respectively. It can be seen that the major 
291 decomposition areas can be divided into three zones, 275 to $350{ }^{\circ} \mathrm{C}, 300$ to $350{ }^{\circ} \mathrm{C}$ and 325 to $400{ }^{\circ} \mathrm{C}$ for $\mathrm{SB}$ coatings,

292 filter papers and Pluronics coatings, respectively. However, an increase in the major decomposition area of both

293 Pluronics was observed when filter papers were coated with the presence of SB (+Pluronics), which can be attributed to 294 an increased adsorption of Pluronics in the presence of SB.
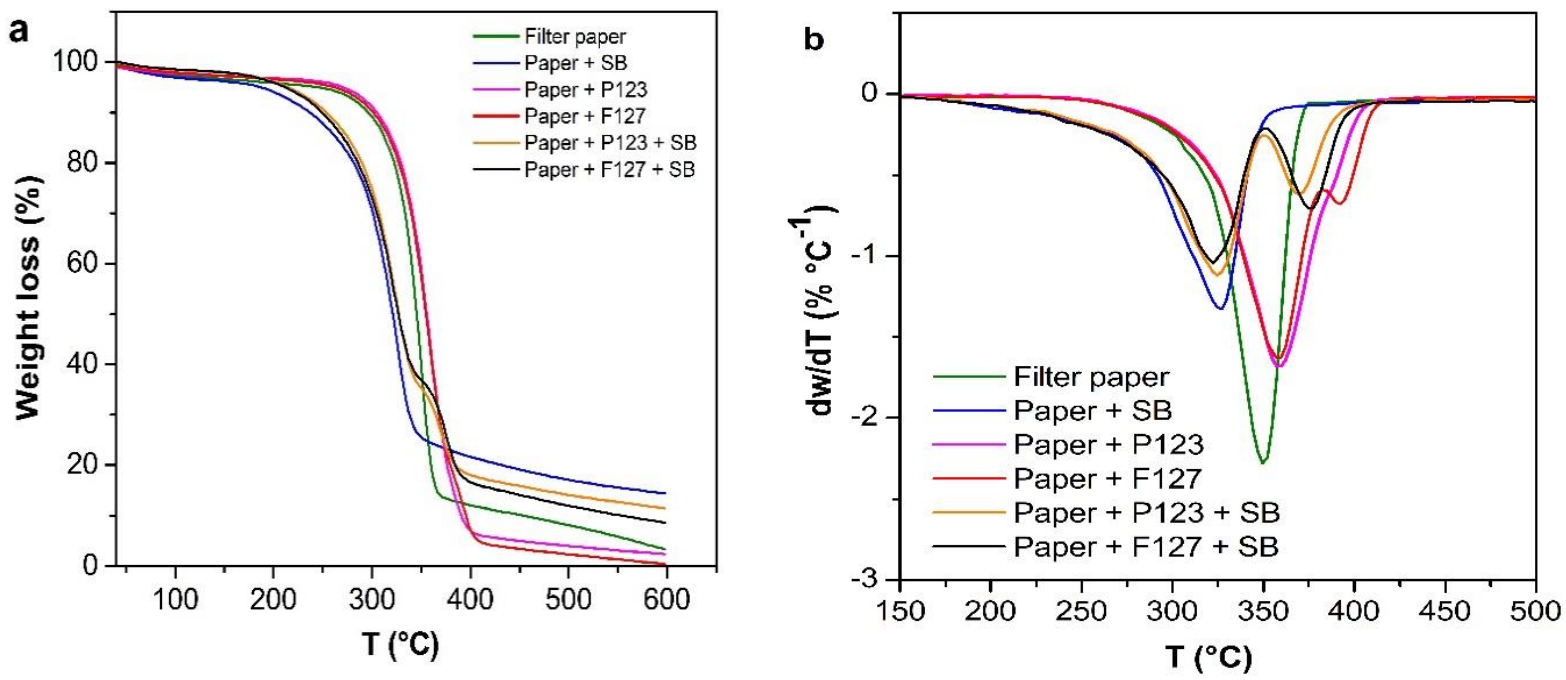

297 Figure 4 TGA (a) and DTG (b) curves for filter paper, paper + SB, paper + P123, paper + F127, paper + P123 + SB and paper + F127 + SB

\section{Optical density}

301 OD is an important parameter to evaluate the depth of the color tone in the printed papers, which clearly affects the perceived saturation of a color ( $\mathrm{Hu}, \mathrm{Fu}, \mathrm{Chu}, \& \mathrm{Lin}, 2017)$. Figure 5 represents the OD of the black color with increasing concentration of SB (A), Pluronics (B), PCC (C) and SB/P123/PCC (D). Figure 5c shows the effect of PCC concentration on OD. OD for PCC coating correlates with the Gurley permeability, attaining deeper tones as the sheet became more resistant to air flow (Kasmani, Mahdavi, Alizadeh, Nemati, \& Samariha, 2013). The highest improvement was observed at $8 \%$ of PCC. Likewise, OD followed the same trends as GA, and thus it increased with increasing concentration of SB and P123/F127. Above all, Figure 5d shows that the highest increase in OD was achieved with the combination of SB-P123-PCC in the coating formulation. 

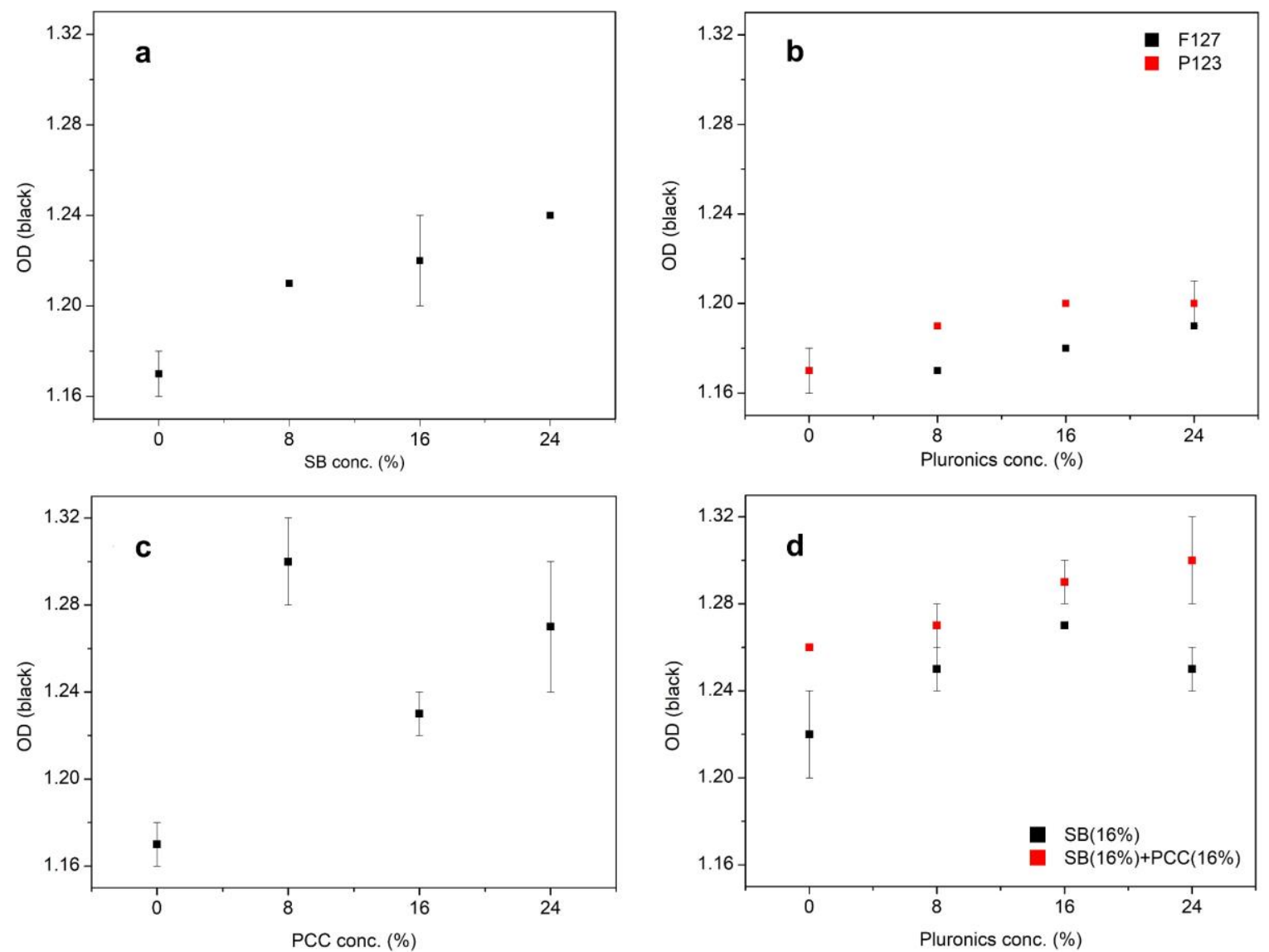

Figure 5 Effect of different concentrations of SB (a), Pluronics (b), PCC (c) and their combinations (d) on OD (0\%:

312 reference coating using NS).

\section{Inter-color bleed (ITCB), print-through (PT) and circularity for black color}

315 Figure 6 presents the ITCB, PT and circularity (black dots) of SB, PCC, P123, SB/P123 and SB/P123/PCC coated

316 papers. Similarly to GA, ITCB was also improved (i.e., reduced) upon the addition of these components. The highest

317 decrease in ITCB, 15.9\%, was observed with SB/P123/PCC coatings. Unlike GA and ITCB, PT of SB/P123 or

318 SB/P123/PCC coated paper showed a higher PT at the concentrations used in this work, due to decrease in viscosity of

319 the coating formulation, letting the formulation go deeper into the cellulose matrix, which increased the see-through of

320 ink from the other (non-coated) side of the paper. The presence of PCC on the cellulosic surface provided a better

321 improvement in the PT compared to SB or P123 coated papers. Circularity of black dots generally correlates with the

322 ITCB, improving with the formulation containing SB and P123, due to better fixation of ink particles onto the surface. 


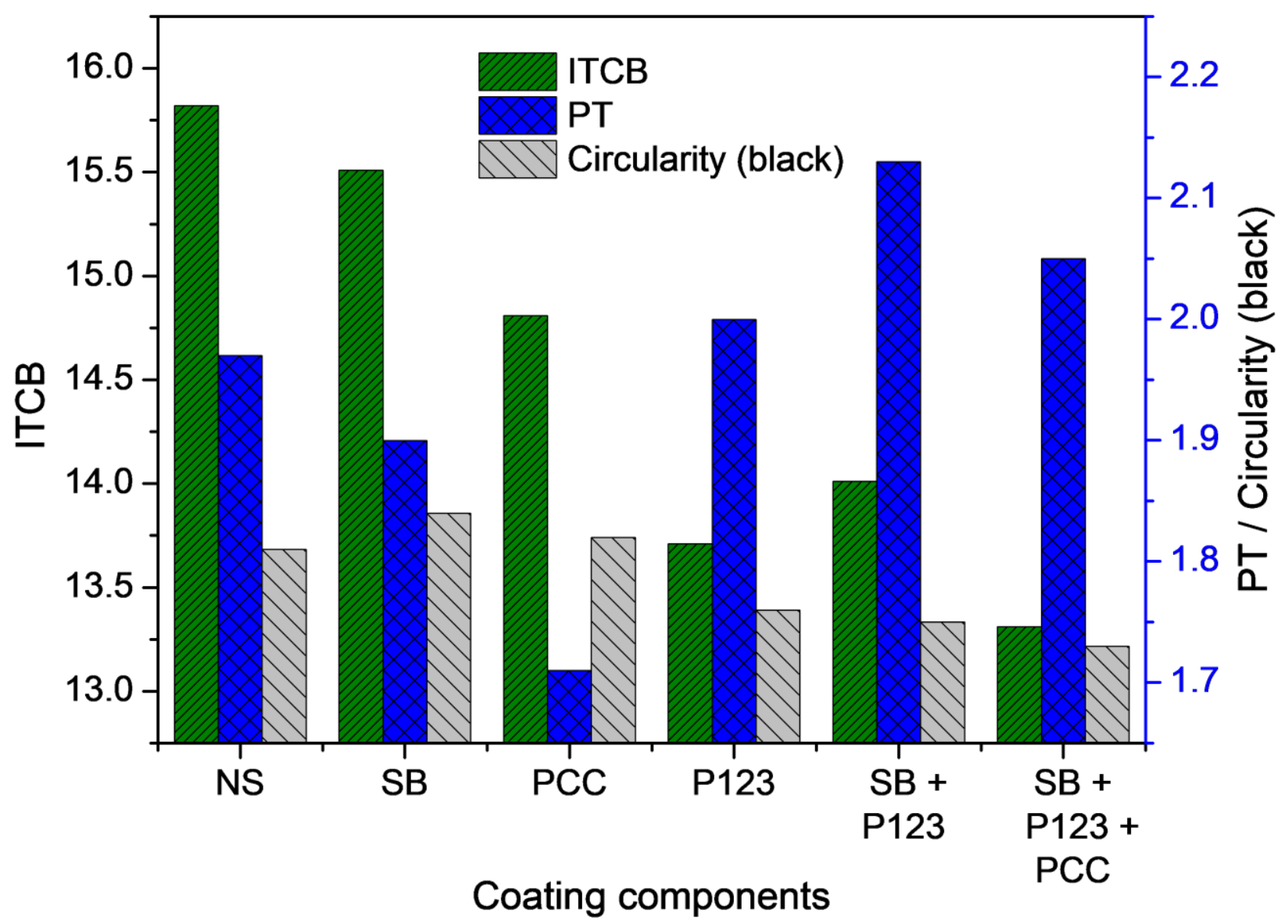

Figure 6 Effect of different coating components on ITCB, PT and circularity of black color.

Whiteness and fluorescence quenching

327 Whiteness, positively correlated with ISO brightness, represents a paper's ability to equally reflect a balance of all 328 wavelength of light across the visible spectrum (Hu et al., 2017). The addition of OBA on the paper surface is a costeffective solution in papermaking to increase the whiteness of printing and writing papers (Shi et al., 2012). Therefore, the interaction between OBA and the other coating components is important. From Table 4, it can be noted that the presence of OBA improved the whiteness of the coated paper but the presence of HCS quenched this agent, resulting in lower whiteness (Figure S1, Supplementary Information). It is also worth mentioning that the presence of P123 and PCC did not show any further improvement in the whiteness.

Table 4 Study of interactions among factors. Percentages are related to the total solids content (on the basis of dry weight) of coating formulations.

\begin{tabular}{|c|c|c|c|c|c|c|c|c|c|c|c|c|}
\hline $\begin{array}{l}\mathrm{HCS} \\
(\%) \\
\end{array}$ & $\begin{array}{l}\text { P123 } \\
(\%) \\
\end{array}$ & $\begin{array}{l}\text { PCC } \\
(\%) \\
\end{array}$ & $\begin{array}{l}\mathrm{OBBA} \\
(\%)\end{array}$ & GA & $\begin{array}{l}\text { OD } \\
\text { (cyan) }\end{array}$ & $\begin{array}{l}\text { OD } \\
\text { (Magenta) }\end{array}$ & $\begin{array}{l}\text { OD } \\
\text { (yellow) }\end{array}$ & $\begin{array}{l}\text { OD } \\
\text { (black) }\end{array}$ & PT & ITCB & $\begin{array}{l}\text { Circularity } \\
\text { (Black) }\end{array}$ & Whiteness \\
\hline 0 & 0 & 0 & 0 & 6512 & 0.76 & 0.87 & 1.31 & 1.23 & 1.6 & 15.5 & 1.95 & 146 \\
\hline 0 & 0 & 0 & 6 & 6301 & 0.74 & 0.84 & 1.31 & 1.17 & 1.97 & 15.8 & 1.81 & 162 \\
\hline 0 & 0 & 16 & 0 & 6596 & 0.76 & 0.88 & 1.33 & 1.20 & 1.56 & 15.4 & 1.98 & 146 \\
\hline
\end{tabular}




\begin{tabular}{|c|c|c|c|c|c|c|c|c|c|c|c|c|}
\hline 0 & 0 & 16 & 6 & |7074 & 0.80 & 0.91 & 1.36 & 1.21 & 1.76 & 14.4 & 1.81 & 162 \\
\hline 0 & 16 & 0 & 0 & 6758 & 0.79 & 0.89 & 1.33 & 1.22 & 1.76 & 14.5 & 1.80 & 146 \\
\hline 0 & 16 & 0 & 6 & 6922 & 0.80 & 0.90 & 1.34 & 1.20 & 1.86 & 13.7 & 1.76 & 162 \\
\hline 0 & 16 & 16 & 0 & 7004 & 0.81 & 0.90 & 1.34 & 1.20 & 1.80 & 14.2 & 1.74 & 146 \\
\hline 0 & 16 & 16 & 6 & 6802 & 0.81 & 0.90 & 1.33 & 1.21 & 1.69 & 14.0 & 1.71 & 163 \\
\hline 8 & 8 & 8 & 3 & 7122 & 0.82 & 0.90 & 1.34 & 1.19 & 1.65 & 13.8 & 1.80 & 148 \\
\hline 8 & 8 & 8 & 3 & 7212 & 0.82 & 0.91 & 1.33 & 1.20 & 1.69 & 14.2 & 1.81 & 147 \\
\hline 16 & 0 & 0 & 0 & 6610 & 0.80 & 0.78 & 1.33 & 1.25 & 1.99 & 16.0 & 1.79 & 144 \\
\hline 16 & 0 & 0 & 6 & 6656 & 0.74 & 0.77 & 1.37 & 1.24 & 1.78 & 16.2 & 1.79 & 145 \\
\hline 16 & 0 & 16 & 0 & 6971 & 0.77 & 0.88 & 1.31 & 1.20 & 1.82 & 15.6 & 1.95 & 144 \\
\hline 16 & 0 & 16 & 6 & 6739 & 0.79 & 0.78 & 1.31 & 1.23 & 1.82 & 15.6 & 1.84 & 146 \\
\hline 16 & 16 & 0 & 0 & 7479 & 0.83 & 0.92 & 1.36 & 1.22 & 1.80 & 12.7 & 1.83 & 146 \\
\hline 16 & 16 & 0 & 6 & 7443 & 0.86 & 0.85 & 1.50 & 1.42 & 1.66 & 16.3 & 1.89 & 146 \\
\hline 16 & 16 & 16 & 0 & 7427 & 0.83 & 0.91 & 1.35 & 1.20 & 1.72 & 13.9 & 1.76 & 145 \\
\hline 16 & 16 & 16 & 6 & 7670 & 0.85 & 0.93 & 1.37 & 1.22 & 1.84 & 13.2 & 1.71 & 148 \\
\hline
\end{tabular}

338 In comparison to NS coatings, whiteness increased by $11 \%$ with the addition of OBA. As aforementioned, HCS (with 339 OBA) reduced the whiteness of coated papers by $10.85 \%$ due to the OBA quenching, irrespective of the presence of 340 any other components. Interestingly, such loss of whiteness was not observed when SB was used instead of the cationic 341 starch ether (Figure S1).

342 To understand the OBA quenching effect in the presence of HCS and SB, fluorescence emission spectra were recorded 343 for solutions containing OBA (1.84 ppm) and either cationic starch (6.1 ppm), so as to keep the same ratio as in coating 344 formulations (6\% OBA / 16\% CS). Fluorescence quenching was clear in the presence of all cationic starches but, in the 345 case of HCS, the intensity of the emission of blue light ( $440 \mathrm{~nm})$ decreased almost by a factor of 4 (Figure 7).

346 Quenching was possibly due to the formation of a non-fluorescent complex, where the sulfonate groups of OBA donate 347 electrons to the quaternary ammonium groups of HCS. Still, the most plausible explanation is the aggregation-caused 348 quenching, where aggregation is promoted by electrostatic interactions. The reason for this is that solutions at higher 349 concentration, such as 9.2 ppm OBA / 24.4 ppm HCS, showed Rayleigh scattering to such extent that no reliable 350 spectrum could be obtained, even though a concentration of $24.4 \mathrm{ppm}$ lies much below the solubility limit of HCS. In 351 other words, there was a phase transition from solution to dispersion when both solutions, each of them displaying 352 negligible light scattering, were mixed. However, regardless of the quenching mechanism, neither this aggregation nor 353 that extent of quenching was observed when using SB/OBA at the same concentrations, supporting the previously 354 described retention of paper whiteness. Given that SB and HCS had the same DS, it may be concluded that the cationic 355 starch ester possesses a key advantage over its ether counterpart. This advantage should, undoubtedly, be further 356 explored. 


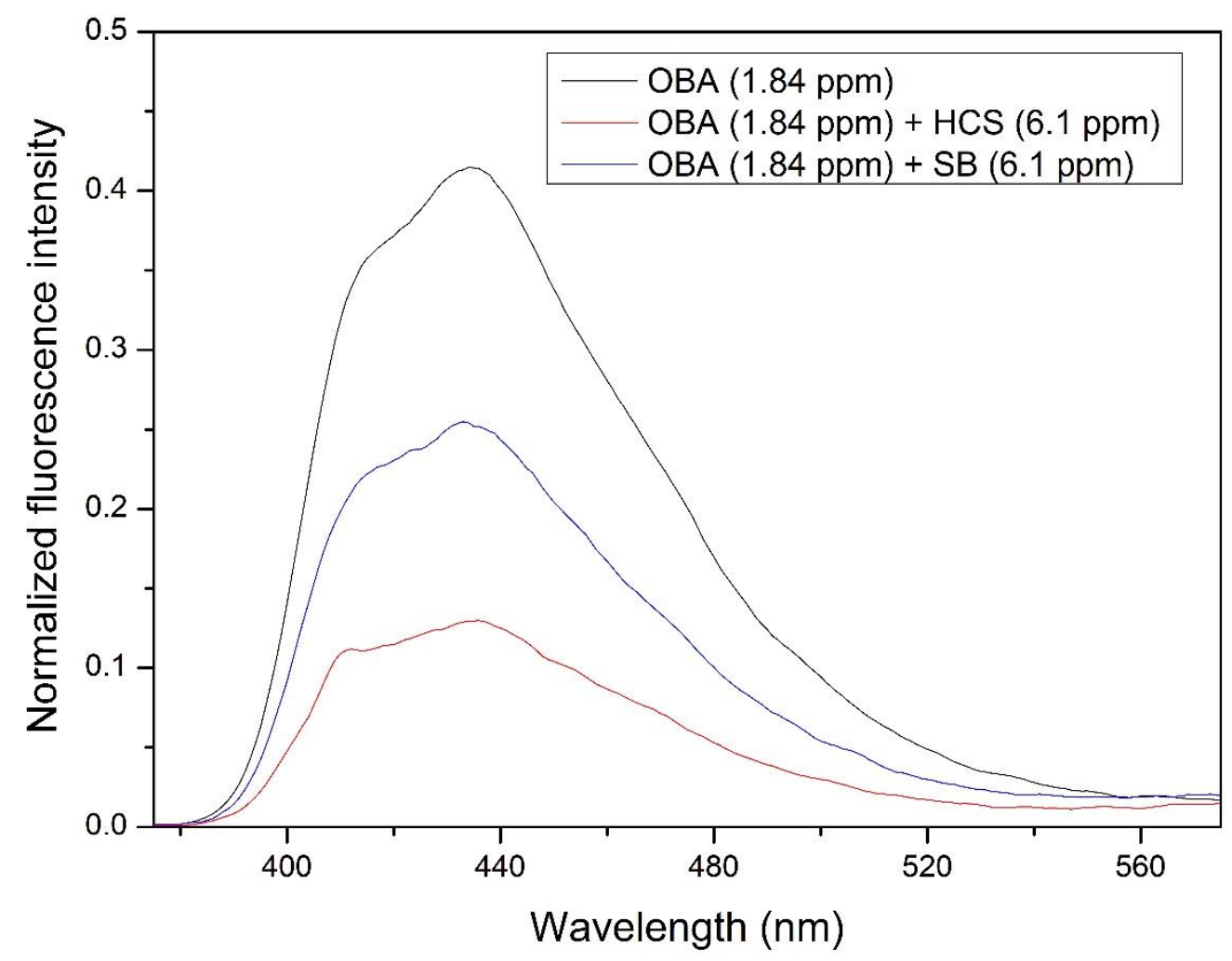

358 Figure 7 Fluorescence emission spectrum of OBA in presence of HCS and SB. An excitation wavelength of $350 \mathrm{~nm}$ was 359 used to record all spectrum.

\section{$361 \quad$ Statistical analysis}

362 Figures 8a and 8b show the half-normal plots, as obtained from JMP software, for all the studied factors. As indicated in

363 Figure 8a, three major factors are clearly falling off from the red straight line. In other words, P123, HCS and their

364 interaction (HCS*P123) can be considered as the most significant factors to affect the GA, whereas PCC and OBA, like

365 their interaction, were found to be insignificant. The model was further optimized through prediction plots and ANOVA

366 study, and insignificant factors were removed. Figure $8 \mathrm{~b}$ indicates the half-normal plot of the model, considering only

367 the significant factors. 

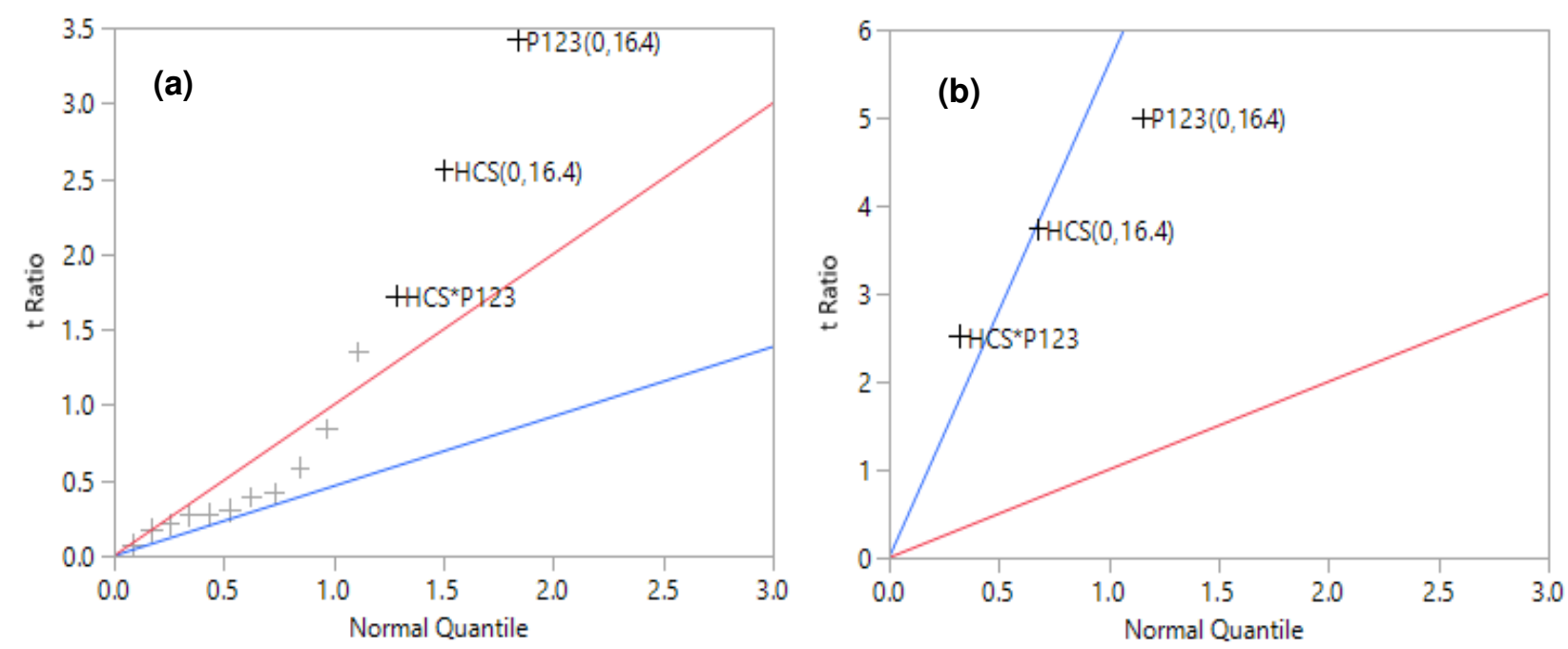

Figure 8 Half-normal plot for gamut area: a) considering all factors; b) considering only significant factors.

A prediction profile for GA and a complete report of the model is provided in the Supplementary Information. From this statistical study, it can be inferred that the combination of HCS and Pluronics in the coating formulation, together with the presence of PCC and OBA, led to improve the printability of coated papers. The statistical study of these components has shown that, for GA, the incorporation of P123, the presence of HCS and their interaction, have significant effect in the selected range. Regarding the most important variables for the other printing properties, P123 has significant effect on OD for cyan/magenta/yellow and on ITCB, whereas HCS impacts OD of black color. The ternary interaction HCS-P123-OBA showed a good impact on PT (not seen with SB-P123-OBA) and the binary interaction P123-PCC affects the circularity of black color. The corresponding half-normal plot, the analysis of variance and the prediction profiles have also been included in the Supplementary Information. All considered, the combination of both HCS and P123, accounting for a total solids content of $16 \%$, has the greatest impact on the overall printing quality.

\section{Conclusions}

385 The effect of an unconventional combination of coating components, highly substituted cationic starch and Pluronics, on 386 the printing quality of office papers was investigated. As a key novelty, cationic starch refers not only to its typical ether 387 form, but also to starch betainate, an ester that has been suggested for bulk addition in sheet forming but not (as far as 388 the authors are concerned) for paper coating. A $24 \%$ coating weight of starch betainate increased the gamut area by 12.5\%, whilst Pluronics P123 and F127 (8\% coating weight) attain improvements of $14.6 \%$ and $11.8 \%$, respectively.

390 Both cationic starches, ether and ester, showed the same outcome for improving the paper printing properties in presence and absence of Pluronics. Nonetheless, while the ether caused a certain loss of whiteness, as it quenches the fluorescence emission of the optical agent, such loss was not found when starch betainate was used. The ability of starch betainate of keeping the whiteness gain of an anionic brightening agent is a key finding of this work. 
394 Remarkably, the statistical analysis indicated that besides the aforementioned individual effects of cationic starch and

395 Pluronics, the binary interaction thereof had a significantly positive influence on the gamut area. Furthermore, the

396 optical density (cyan, magenta, yellow and black), print-through, inter-color bleed and circularity were successfully

397 correlated with the independent variables. It was shown, for instance, that the print-through was significantly affected by

398 the presence of conventional cationic starch, OBA and Pluronic P123.

399

400 Declarations

$401 \quad$ Funding

402 This work was carried out under the Project inpactus -innovative products and technologies from eucalyptus, Project N.

40321874 funded by Portugal 2020 through European Regional Development Fund (ERDF) in the frame of COMPETE

$4042020 \mathrm{n}^{\circ} 246 /$ AXIS II/2017. Authors would like to thank the Coimbra Chemical Centre, which is supported by the

405 Fundação para a Ciência e a Tecnologia (FCT), through the projects UID/QUI/00313/2020 and COMPETE. Authors

406 would also like to thank the CIEPQPF - Strategic Research Centre Project UIDB/00102/2020, funded by the Fundação

407 para a Ciência e Tecnologia (FCT). M.S. acknowledges the PhD grant BDE 03|POCI-01-0247-FEDER-021874. R.A.

408 acknowledges the post-doc grant BPD 02|POCI-01-0247-FEDER-021874.

\section{Conflicts of interest/Competing interests}

410 The authors declare that there is no conflict of interest and that they do not have competing interests.

\section{Availability of data and material}

412 All data are displayed in the article and its electronic supplementary information.

\section{Code availability}

414 Not applicable.

415 Authors' contributions

416 All authors made substantial contributions to the conception of the work, the acquisition and interpretation of data, and

417 writing. All authors approve the manuscript. All authors agree to be accountable for all aspects of the work in ensuring

418 that questions related to the accuracy or integrity of any part of the work are appropriately investigated and resolved.

\section{$419 \quad$ Ethics approval}

420 Not applicable. No studies involving humans and/or animals. 
Not applicable. No studies involving humans and/or animals.

\section{Consent for publication}

424 Not applicable. No studies involving humans and/or animals.

\section{References}

Alexandridis, P., Holzwarthf, J. F., \& Hatton, T. A. (1994). Micellization of Poly(ethylene oxide)-Poly(propylene oxide)-Poly(ethylene oxide) Triblock Copolymers in Aqueous Solutions Thermodynamics of copolymer Association. Macromolecules, 27, 2414-2425.

Auzély-Velty, R., \& Rinaudo, M. (2003). Synthesis of starch derivatives with labile cationic groups. International Journal of Biological Macromolecules, 31(4-5), 123-129.

Baptista, J. G. C., Rodrigues, S. P. J., Matsushita, A. F. Y., Vitorino, C., Maria, T. M. R., Burrows, H. D., ... Valente, A. J. M. (2016). Does poly(vinyl alcohol) act as an amphiphilic polymer? An interaction study with simvastatin. Journal of Molecular Liquids, 222, 287-294.

Bendoraitiene, J., Lekniute-Kyzike, E., \& Rutkaite, R. (2018). Biodegradation of cross-linked and cationic starches. International Journal of Biological Macromolecules, 119, 345-351.

Bollström, R., Tobjörk, D., Dolietis, P., Salminen, P., Preston, J., Österbacka, R., \& Toivakka, M. (2013). Printability of functional inks on multilayer curtain coated paper. Chemical Engineering and Processing: Process Intensification. https://doi.org/10.1016/j.cep.2012.07.007

Gao, J., Luo, Z., Fu, X., Luo, F., \& Peng, Z. (2012). Effect of enzymatic pretreatment on the synthesis and properties of phosphorylated amphoteric starch. Carbohydrate Polymers, 88(3), 917-925. https://doi.org/10.1016/j.carbpol.2012.01.034

Gigac, J., Stankovská, M., Opálená, E., \& Pažitný, A. (2016). The effect of Pigments and Binders on Inkjet Print Quality. Wood Research, 61(2), 215-226.

Gigac, J., Stankovska, M., \& Pazitny, A. (2016). Influence of the Coating Formulations and Base Papers on Inkjet Printability. Wood Research, 61(6), 915-926.

Granö, H., Yli-Kauhaluoma, J., Suortti, T., Käki, J., \& Nurmi, K. (2000). Preparation of starch betainate: a novel cationic starch derivative. Carbohydrate Polymers, 41(3), 277-283.

Haack, V., Heinze, T., Oelmeyer, G., \& Kulicke, W. M. (2002). Starch derivatives of high degree of functionalization, 8 synthesis and flocculation behavior of cationic starch polyelectrolytes. Macromolecular Materials and Engineering, 287(8), 495-502.

He, Z., \& Alexandridis, P. (2018). Micellization thermodynamics of Pluronic P123 (EO20PO70EO20) amphiphilic block copolymer in aqueous Ethylammonium nitrate (EAN) solutions. Polymers, 10(32).

Hebeish, A., Higazy, A., El-Shafei, A., \& Sharaf, S. (2010). Synthesis of carboxymethyl cellulose (CMC) and starchbased hybrids and their applications in flocculation and sizing. Carbohydrate Polymers, 79(1), 60-69.

Hu, G., Fu, S., Chu, F., \& Lin, M. (2017). Relationship between paper whiteness and color reproduction in inkjet printing. BioResources, 12(3), 4854-4866. https://doi.org/10.15376/biores.12.3.4854-4866

Huber, K. C., \& BeMiller, J. N. (2001). Location of sites of reaction within starch granules. Cereal Chemistry, 78(2), 173-180. https://doi.org/10.1094/CCHEM.2001.78.2.173

Kasmani, J. E., Mahdavi, S., Alizadeh, A., Nemati, M., \& Samariha, A. (2013). Physical properties and printability characteristics of mechanical printing paper with LWC. BioResources, 8(3), 3646-3656. https://doi.org/10.15376/biores.8.3.3646-3656

Lamminmäki, T. T., Kettle, J. P., \& Gane, P. A. C. (2011). Absorption and adsorption of dye-based inkjet inks by coating layer components and the implications for print quality. Colloids and Surfaces A: Physicochemical and Engineering Aspects, 380(1-3), 79-88.

Lee, H. L., Shin, J. Y., Koh, C.-H., Ryu, H., Lee, D.-J., \& Sohn, C. (2002). Surface sizing with cationic starch: its effect on paper quality and the papermaking process. Tappi Journal, 1(1), 34-40.

Liu, X., Vesterinen, A. H., Genzer, J., Seppälä, J. V., \& Rojas, O. J. (2011). Adsorption of PEO-PPO-PEO triblock copolymers with end-capped cationic chains of poly(2-dimethylaminoethyl methacrylate). Langmuir. 
https://doi.org/10.1021/la201596x

Liu, X., Wu, D., Turgman-Cohen, S., Genzer, J., Theyson, T. W., \& Rojas, O. J. (2010). Adsorption of a nonionic symmetric triblock copolymer on surfaces with different hydrophobicity. Langmuir. https://doi.org/10.1021/la100156a

Lourenço, A. F., Gamelas, J. A. F., Sarmento, P., \& Ferreira, P. J. T. (2020). Cellulose micro and nanofibrils as coating agent for improved printability in office papers. Cellulose, 27(10), 6001-6010. https://doi.org/10.1007/s10570020-03184-9

Lundberg, A., Örtegren, J., Norberg, O., \& Wågberg, K. (2010). Improved print quality by surface fixation of pigments. International Conference on Digital Printing Technologies, (February), 251-255.

Niegelhell, K., Chemelli, A., Hobisch, J., Griesser, T., Reiter, H., Hirn, U., \& Spirk, S. (2018). Interaction of industrially relevant cationic starches with cellulose. Carbohydrate Polymers, 179, 290-296.

Petkova-Olsson, Y., Altun, S., Ullsten, H., \& Järnström, L. (2017). Temperature effect on the complex formation between Pluronic F127 and starch. Carbohydrate Polymers, 166, 264-270.

Petkova-Olsson, Y., Ullsten, H., \& Järnström, L. (2016). Thermosensitive silica-pluronic-starch model coating dispersion-part I: The effect of Pluronic block copolymer adsorption on the colloidal stability and rheology. Colloids and Surfaces A: Physicochemical and Engineering Aspects, 506, 245-253. https://doi.org/10.1016/j.colsurfa.2016.06.032

Sharma, M., Aguado, R., Murtinho, D., Valente, A. J. M., \& Ferreira, P. J. T. (2021). International Journal of Biological Macromolecules Novel approach on the synthesis of starch betainate by transesteri fi cation. International Journal of Biological Macromolecules, 182, 1681-1689. https://doi.org/10.1016/j.ijbiomac.2021.05.175

Sharma, M., Aguado, R., Murtinho, D., Valente, A. J. M., Mendes De Sousa, A. P., \& Ferreira, P. J. T. (2020, November 1). A review on cationic starch and nanocellulose as paper coating components. International Journal of Biological Macromolecules, Vol. 162, pp. 578-598. https://doi.org/10.1016/j.ijbiomac.2020.06.131

Shi, H., Liu, H., Ni, Y., Yuan, Z., Zou, X., \& Zhou, Y. (2012). Review: Use of optical brightening agents (OBAs) in the production of paper containing high-yield pulps. BioResources, 7(2), 2582-2591. https://doi.org/10.15376/biores.7.2.2582-2591

Sousa, S., De Sousa, A. M., Reis, B., \& Ramos, A. (2014). Influence of Binders on Inkjet Print Quality. Materials Science, 20(1). https://doi.org/10.5755/j01.ms.20.1.1998

Stankovská, M., Gigac, J., Letko, M., \& Opálená, E. (2014). The Effect of Surface Sizing on Paper Wettability and on Properties of Inkjet Prints. Wood Research, 59(1), 67-76.

Thapa, R. K., Cazzador, F., Grønlien, K. G., \& Tønnesen, H. H. (2020). Effect of curcumin and cosolvents on the micellization of Pluronic F127 in aqueous solution. Colloids and Surfaces B: Biointerfaces, 195(July 2020). https://doi.org/10.1016/j.colsurfb.2020.111250

Wang, S., \& Cheng, Q. (2009). A novel process to isolate fibrils from cellulose fibers by high-intensity ultrasonication, Part 1: Process optimization. Journal of Applied Polymer Science, 113(2), 1270-1275. 


\section{Supplementary Files}

This is a list of supplementary files associated with this preprint. Click to download.

- supplementarymaterial.doc 